\title{
KAJIAN TRANSFORMASI VISUAL DESAIN KARAKTER BULBASAUR PADA GAME POKEMON GO GENERASI I
}

\author{
Ricky Widyananda Putra, Arief Ruslan \\ Fakultas Ilmu Komunikasi Universitas Budi Luhur \\ Email: ricky_wputra@yahoo.co.id, Arief.ruslan.90@gmail.com
}

\begin{abstract}
Game Pokemon Go is one form of representation of the culture medium which presents a simulated world by building signs in it through the storyline, gameplay, environments, and characters the game, so it becomes a digital culture. Pokemon character design, in this case is Bulbasaur, capable of causing factors curious and addicted to the players as a result of the application of methods mangamatrix, color theory, and techniques of morphological forced connections through visual transformation of character design. This study is a qualitative research based on the application of the principle of manga-matrix includes internal and external factors on the character, the analysis of similarities or relationships between theories related to visual elements and interpretation of the meaning of the characters, as well as a mix of theories on character designs reflecting the ideology of Satoshi Tajiri in terms implementation of Japanese culture. The identification results of data analysis visual transformation of the character designs Bulbasaur has much in common with the presence of additional elements on the diversity of character visualization Bulbasaur. Variety Bulbasaur form the foundation for thinking and the creation of the character as a media introduction of visual transformation of a game character design.
\end{abstract}

Keywords: Game, Character, Manga Matrix, Pokemon GO, Transformation Visual design

\begin{abstract}
ABSTRAK
Game Pokemon Go merupakan salah satu wujud representasi dari kebudayaan media yang menyajikan sebuah dunia simulasi dengan membangun tandatanda di dalamnya melalui storyline, gameplay, environment, maupun karakter-karakter game, sehingga menjadi sebuah budaya digital. Desain karakter Pokemon, dalam hal ini adalah Bulbasaur, mampu menimbulkan faktor penasaran dan kecanduan pada pemainnya akibat penerapan metode manga- matrix, teori warna, dan teknik morphological forced connections melalui transformasi visual desain karakternya. Penelitian ini merupakan penelitian kualitatif berdasarkan penerapan prinsip manga-matrix meliputi faktor internal dan eksternal pada karakter, analisis persamaan atau relasi antar teori yang berkaitan dengan unsur visual dan interpretasi makna karakter, serta perpaduan teori-teori pada desain karakter sebagai cerminan ideologi Satoshi Tajiri dalam hal implementasi kebudayaan Jepang. Hasil identifikasi analisis data transformasi visual desain karakter Bulbasaur
\end{abstract}


memiliki persamaan dengan keberadaan elemen-elemen tambahan pada keragaman bentuk visualisasi karakter Bulbasaur. Ragam bentuk Bulbasaur tersebut menjadi dasar pemikiran dan penciptaan karakter sebagai media pengenalan transformasi visual desain karakter suatu game.

\section{Kata kunci: Game, Karakter, Manga Matrix, Pokemon GO, Transformasi Visual desain}

\section{PENDAHULUAN}

Manusia memiliki berbagai kebutuhan untuk memenuhi keinginan atau hasrat hidupnya. Kebutuhan ini dapat berupa kebutuhan primer dan kebutuhan sekunder. Hasrat atau keinginan untuk memenuhi kebutuhan hidup ini dapat saling melengkapi dan bahkan dapat bertukar tempat (posisi), misalnya adakalanya kebutuhan sekunder justru menempati urutan pertama bagi manusia memenuhi kebutuhan hidupnya. Hal tersebut dapat dilihat dalam aspek hiburan. Hiburan merupakan salah satu kebutuhan sekunder manusia, namun saat ini dapat dikatakan telah menjadi kebutuhan pokok selain sandang, papan, dan pangan. Kenyataan tersebut dapat dilihat bahwa kebutuhan hiburan di negara ini cukup tinggi, misalnya bagaimana masyarakat membutuhkan acara di televisi, radio, panggung hiburan, hingga video games.
Games bukanlah fenomena baru lagi sebagai alat hiburan, Saat ini, setiap masyarakat sudah dibekali oleh games di mana-mana. Hal ini bisa ditemukan dalam contoh yang paling kecil, yaitu hand phone. Sadar atau tidak, kita sudah dibekali dengan games, entah mau dimainkan atau tidak. Saat ini, games telah menjadi kebiasaan orang untuk "menghibur" diri, apalagi kini ditunjang dengan kemajuan teknologi. Hal tersebut dapat dilihat dari visual dan audio yang terlihat nyata, efek yang indah, cerita yang menarik, dan juga berinteraksi langsung.

Salah satu genre game yakni roleplaying game (RPG) merupakan permainan dengan tingkat kompleksitas yang cukup tinggi. RPG bukan hanya permainan yang hanya bertujuan untuk menyelesaikan misi, melainkan lebih ditekankan pada kemampuan pengembangan atau building system. Perbedaan tingkatan (level) 
yang ada dalam game merupakan media pembeda antara karakter satu dengan yang lain meliputi: kekuatan, tampilan visual, sifat, dan sebagainya. Perbedaan tersebut tidak hanya terbatas pada karakter saja, melainkan juga perbedaan pengembangan skill dan item dalam sebuah permainan.

Berkaitan dengan hal di atas, dalam penelitian ini penulis akan menganalisis game Pokemon Go Generasi I, yang rilis pada tahun 2016 oleh perusahan bernama Niantic dan sudah dirilis pada 26 Negara. Pokemon GO merupakan salah satu contoh permainan digital yang menggunakan peran multimedia dalam penyebarannya, dengan menciptakan faktor keingintahuan (curiousity) penggemarnya melalui karakterkarakter Pokemon yang mampu bertransformasi, berubah menjadi karakter lain dengan kemampuan yang berbeda. Kehadiran game Pokemon GO telah menjadi semangat globalisasi dengan menampilkan pertukaran bendabenda/simbol-simbol, pergerakan antar tempat dikombinasikan dengan perkembangan teknologi komunikasi, serta pertemuan dan percampuran kebudayaan dalam era digital. Konsep game Pokemon GO menekankan pada kemampuan berkomunikasi, location based service untuk menentukan lokasi pemain secara otomatis, accelerometer, dan lain-lain ke dalam genre $R P G$ yang lebih mendekati social game, melalui interaksi (pertemanan maupun konfrontasi pemain dalam game), serta dapat membentuk kelompok berdasarkan lokasi geografis.

Penelitian ini akan dibatasi dengan menggunakan metode Mangamatrix untuk pengkajian studi karakter (dalam hal ini pada karakter komik Jepang/manga), dikombinasikan dengan teknik morphological forced connections dan teori warna untuk mengupas studi kasus karakter game Pokemon GO untuk mengidentifikasi, menjelaskan dan memberikan pemahaman lebih lanjut tentang transformasi visual desain karakter Bulbasaur dalam game Pokemon GO. 


\section{TINJAUAN PUSTAKA}

Perlu dijelaskan terlebih dahulu tentang topik yang akan disorot dan dikaji lebih lanjut mengenai fenomena-fenomena yang berkaitan dengan ketertarikan terhadap sesuatu (game), metode manga-matrix, teori warna, teknik morphological forced connections tentang perwujudan visual karakter game yang menjadi bagian dari game Pokemon GO. Sebagaimana yang diungkapkan oleh Schell (2008:101) dalam salah satu bab bukunya, The Power of Pokemon, tentang bagaimana sejarah atau awal mula game Pokemon berkembang menjadi salah satu game dengan kekuatan yang fenomenal melalui transmedia dan fitur-fitur yang ditampilkan melalui komik, serial animasi, merchandise, hingga sequel game yang terencana dengan baik dan terbangun secara konsisten serta berkesinambungan. Kekuatan Pokemon tersebut tak hanya pada konsep game semata, namun juga karena peran multimedia sebagai sarana yang menjadikannya sebagai fenomena di dunia game. Pola pikir atau ideologi yang diterapkan dalam game Pokemon GO adalah pada proses penciptaan desain karakter monster-monster dari Pokemon. Tim kreator game Pokemon membuat desain karakter Pokemon satu per satu, bukan hanya bentuk dan ukurannya saja, tetapi juga sifat-sifat tertentu dari monster-monster tersebut. Menurut Tajiri (kreator Pokemon), setiap karakter Pokemon harus memiliki sifat-sifat yang unik dan mempunyai nama.

Tabel 1 Penggunaan dan Posisi Teori dalam Penelitian.

\begin{tabular}{|c|c|}
\hline Teori & Penerapan Teori \\
\hline $\begin{array}{l}\text { TEORI MANGA-MATRIX } \\
\text { - Penciptaan karakter (bentuk, } \\
\text { kostum/warna, sifat). } \\
\text { - Kombinasi elemen-elemen } \\
\text { organik dan anorganik pada } \\
\text { karakter. } \\
\text { TEORI WARNA } \\
\text { - Pengertian makna simbolis dan } \\
\text { makna psikologis }\end{array}$ & $\begin{array}{l}\text { - Curiousity -Addictive factors. } \\
\text { Penciptaan dan } \\
\text { visualisasi karakter } \\
\text { (bentuk, kostum/ } \\
\text { warna, sifat) dengan } \\
\text { matriks elemen organik } \\
\text { dan anorganik. } \\
\text { Penerapan kombinasi } \\
\text { warna- warna sebagai }\end{array}$ \\
\hline
\end{tabular}


- Pemahaman sifat-sifat dan efek psikologis warna.

- Kombinasi penggunaan warna pada karakter berdasarkan sifat tertentu. TEKNIK MORPHOLOGICAL FORCED CONNECTIONS

- Penghubung parameter objek kajian.

- Kombinasi elemen dan eksplorasi kemungkinan pemecahan masalah.

\section{Teori Manga-Matrix}

Berdasarkan buku Manga Matrix karangan Hiroyoshi Tsukamoto (2006: 14-15) metode matriks yang digunakan untuk menciptakan karakter menggunakan metode matematik. "Matriks" dalam matematika merupakan sebuah pembagian beberapa angka atau huruf yang di susun kedalam sebuah tabel yang berisi kolom - kolom dan baris - baris. Semua unsur yang ada di alam semesta bisa digunakan untuk menciptakan sebuah karakter dengan merubahnya kedalam bentuk simbol dan menempatkan simbol - pendekatan sifat psikologis karakter Pokemon.

- Perwujudan prinsipprinsip estetik dalam karakter game.

$$
\downarrow
$$

Analisis korelasi antar teori referensi dalam proses transformasi visual desain karakter game Pokemon GO. simbol tersebut pada kolom dan baris pada tabel. Dengan memplot saling silang antara unsur - unsur pada kolom dan baris tersebut kita dapat menciptakan karakter yang beraneka ragam. Unsur - unsur yang ada bisa dikombinasikan sampai tak terbatas jumlahnya sehingga dapat memproduksi sebuah hasil karya cipta yang lebih cemerlang. Menciptakan sesuatu dari nol bisa menjadi sulit walaupun untuk seorang kreator yang ahli sekalipun. Tetapi, dengan metode matriks, kita dapat menciptakan karakter tanpa batas melebihi apa yang kita kira. 


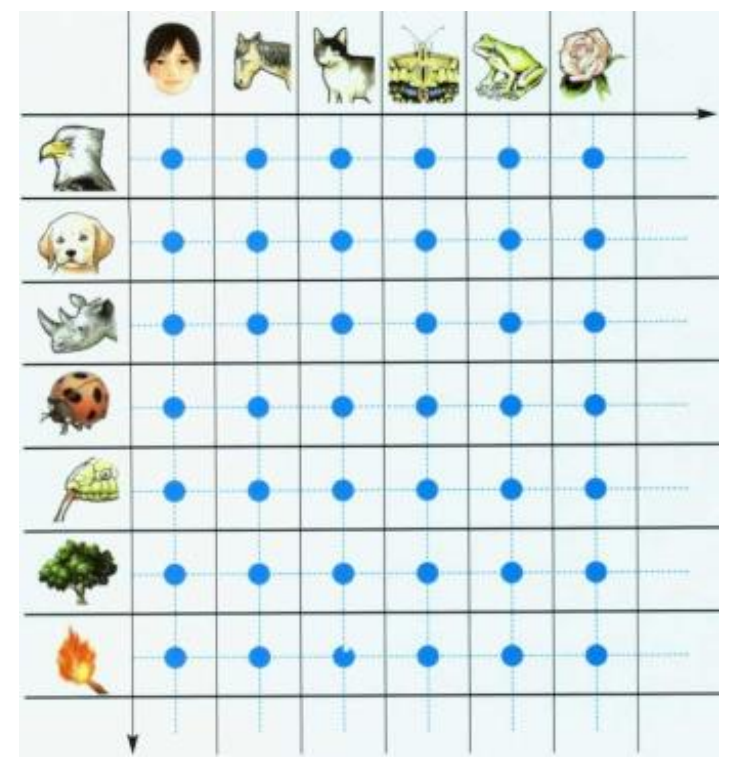

Gambar 1 Diagram Manga-Matrix Hiroyoshi Tsukamoto

Metode dalam menciptakan sebuah karakter dengan kemungkinan tak terbatas dibagi menjadi 3 , yaitu:

1. Form Matrix (Matriks Bentuk)

Perwujudan yang berdasarkan struktur dan bentuk dari badan karakter. semua elemen di dunia ini bisa digunakan sebagai material untuk menjadi bentuk dari karakter. Dengan mengkombinasikan elemen elemen tersebut dapat tercipta makhluk hidup yang baru. Objek - objek yang di tidak nyata juga dapat memberikan kemungkinan untuk dikombinasikan.

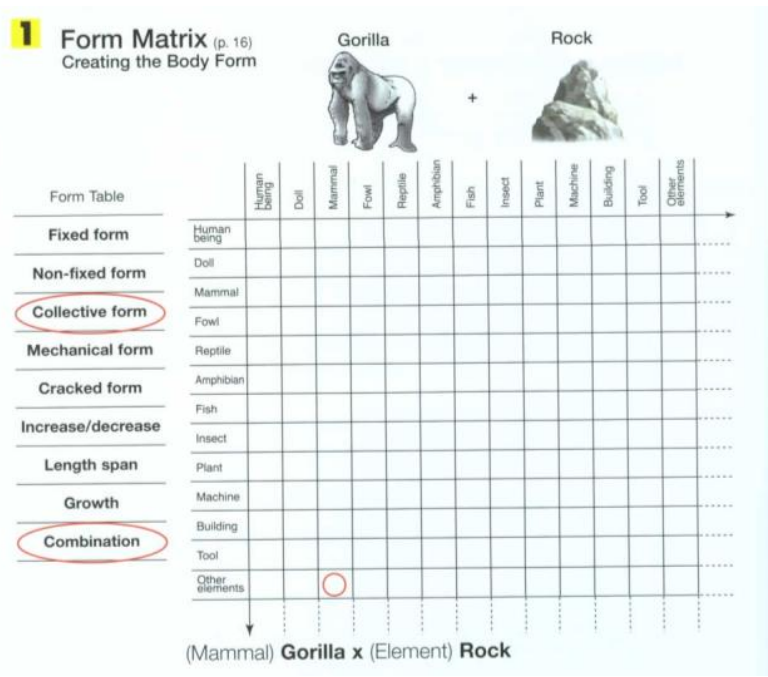

Gambar 2 Diagram Form Matrix Hiroyoshi Tsukamoto

Kostum) 
Setelah karakter secara fisik telah baru lahir kedunia. Ia dapat dibentuk, karakter tersebut dapat diberikan berbagai macam dikatakan sebagai makhluk yang pakaian atau memiliki aksesoris.

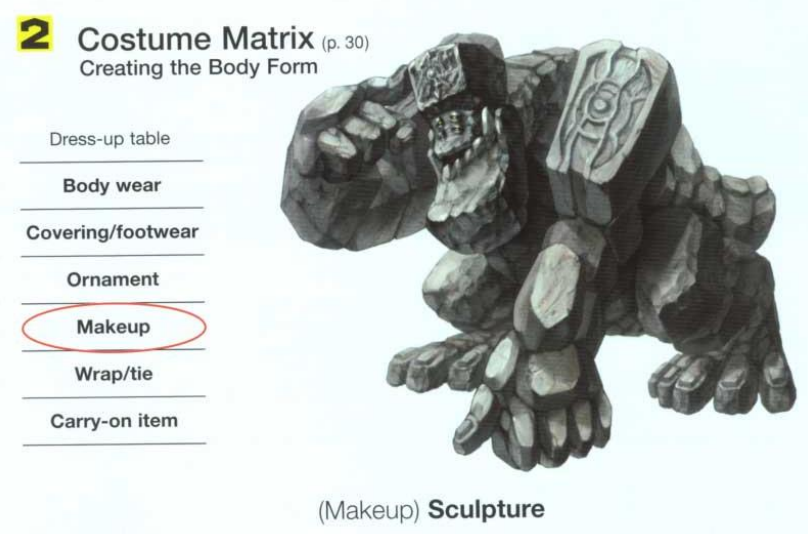

Gambar 3 Diagram Costume Matrix Hiroyoshi Tsukamoto

3. Personality Matrix (Matriks Sifat)

Karena karakter yang diciptakan hanya dari khayalan kosong, karakter tersebut tidak memiliki kepribadian. karakter tersebut merupakan sebuah kertas kosong yang dapat kita berikan kepribadian didalamnya.

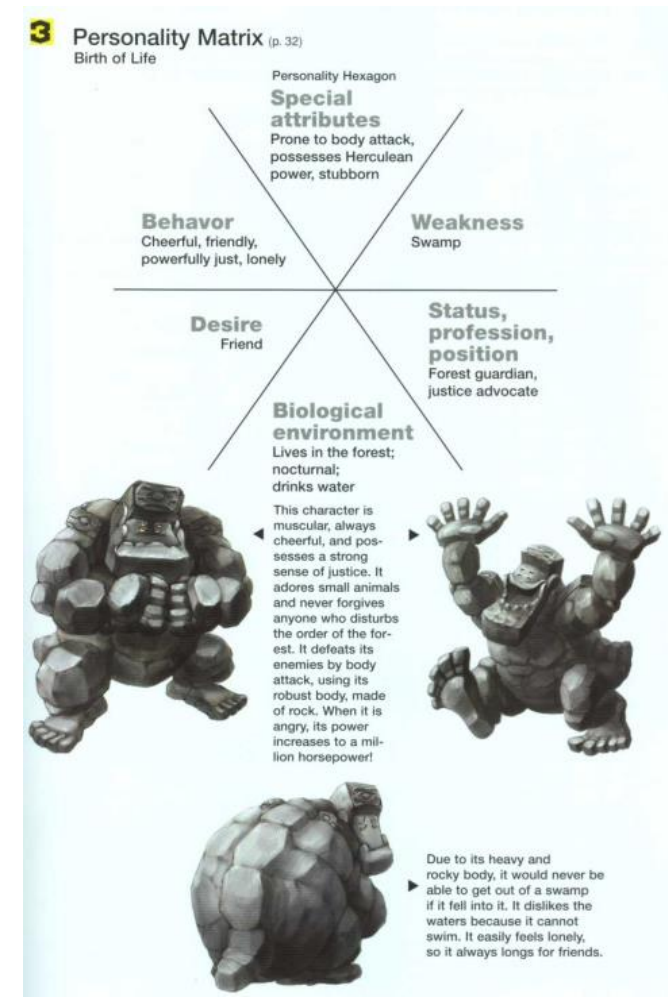




\section{Teori Warna}

Berdasarkan pemaparan Brewster dalam Sulasmi Darmaprawira W.A. (2002: 10), Teori Brewster adalah teori yang menyederhanakan warna yang ada di alam menjadi 4 kelompok warna. Keempat kelompok warna tersebut, yaitu: warna primer, sekunder, tersier, dan warna netral. Kelompok warna ini sering disusun dalam lingkaran warna brewster. Lingkaran warna brewster mampu menjelaskan teori kontras warna (komplementer), split komplementer, triad, dan tetrad. Hasil pengembangan teori Newton dan Munsell yang digunakan untuk mengkaji faktor penggunaan warna serta pemahaman tentang makna warna secara simbolis dan psikologis terhadap karakter game.

\section{Perlambangan Warna}

Perlambang berasal dari kata lambang artinya tanda atau yang menyatakan suatu hal atau mengandung suatu maksud tertentu. Warna sebagai perlambang sudah dikenal sejak masa yang lampau. Dimana warna dipergunakan untuk melambangkan kekuatan-kekuatan alam, melakukan interaksi sosial, ataupun pada acara-acara ritual. Pengenalan bentuk merupakan proses perkembangan intelektual, sedangkan warna merupakan proses intuisi (Samara, 2003 : 30-32). Berikut merupakan perlambangan dari warna :

1. Warna panas/hangat ; keluarga kuning, jingga, merah. Sifatnya : positif, agresif, aktif, merangsang.

2. Warna dingin/sejuk : Keluarga hijau, biru, unggu. Sifatnya : negative, mundur, tenang, tersisih, aman.

3. Hitam Kekuatan, seksualitan, kemewahan, kematian, misteri, ketakutan, ketidakbahagiaan, keanggunan.

4. Putih Kemurnian/suci, bersih, kecermatan, inocent (tanpa dosa), steril, kematian.

5. Merah Identik dengan kekuatan, bertenaga, kehangatan, nafsu, cinta, agresifitas, bahaya. Warna 
merah memiliki efek emosional yang tajam dibandingkan dengan warna lainnya.

6. Biru Kental dengan nuansa rasa kepercayaan, konservatif, keamanan, teknologi, kebersihan, perintah (sering digunakan sebagai warna dasar logo perbankkan, psikologi biru adalah warna yang menandakan adanya unsur kepercayan. Termasuk kepercayaan nasabah kepada bank, juga sebaliknya.)

7. Hijau Memiliki makna alami, kesehatan, pandangan yang enak dilihat mata, kecemburuan, pembauran (Hijau merupakan warna yang dimiliki alam (hutan berwana hijau bila dilihat dari angkasa). Dengan adanya isu global warming belakangan ini tentang pengerusakan alam oleh adanya efek rumah kaca, warna hijau diasosiasikan sebagai warna yang seharusnya lebih banyak ada di Bumi saat ini, ironisnya hanya sebagian orang yang peduli akan lingkungan saja, yang sering berkampanye dengan warna "teduh" ini.
8. Coklat : dapat dipercaya, nyaman, bertahan.

9. Abu-abu : Intelek, futuristik, modis, kesenduan, merusak.

10. Kuning: Optimis, harapan, filosofi, ketidak jujuran/kecurangan, pengecut, penghianatan.

11. Ungu : Spiritual, misteri, keagungan, perubahan bentuk, galak, arogan

12. Orange : Energi, keseimbangan, kehangatan.

\section{Morphological}

Forced

\section{Connections}

Sesuai pemaparan Koberg dan Bagnall (1981:46) sebagai metode penyatuan otomatis parameterparameter ke dalam suatu kombinasi baru sebagai tahapan pemecahan masalah.

Teori-teori yang dipergunakan dalam penelitian ini satu sama lain saling terikat dan melengkapi, yang menjadi dasar pijakan penelitian mengenai pembahasan transformasi visual desain karakter Pokemon dalam game PokemonGO. 


\section{METODE PENELITIAN}

Game Pokemon GO merupakan game dengan genre RPG yang memiliki kelebihan berupa maknamakna dan simbol budaya pada unsur-unsur karakter, serta gameplay yang dibangun di dalamnya. Makna-makna tersebut muncul berdasarkan pengalaman masa kecil, tradisi, maupun penyederhanaan informasi pengetahuan tentang alam dan fenomena masyarakat Jepang sebagai konsep awal pemikiran desain karakter game Pokemon. Usaha untuk mengangkat dan mengenalkan kebudayaan maupun karakteristik sistem tata nilai masyarakat Jepang terlihat dalam game dan animasi Pokemon seperti: budaya hormat pada orang tua atau yang dituakan, budaya rasa malu dan sikap meminta maaf pada setiap kesalahan, budaya kelompok, budaya sistem hierarki senioritas (nenkoujoretsu), optimisme, kemandirian, kewajiban untuk melakukan setiap tanggung jawab sebaik-baiknya, dan sebagainya yang ditampilkan secara tidak langsung atau yang bersifat semiotik (Suryohadiprojo, 1982: 127).

Creswell (2007:15) memaparkan tentang penelitian dengan pendekatan kualitatif, yang dalam hal ini dilakukan berdasarkan studi kasus yakni penelitian tentang entitas tunggal atau fenomena (kasus) dari suatu masa tertentu dan aktivitas (bisa berupa program, kejadian, proses, institusi atau kelompok sosial), melalui pengumpulan detil informasi dengan menggunakan berbagai prosedur pengumpulan data selama kasus itu terjadi.

Penelitian mengenai kajian transformasi visual desain karakter game Pokemon GO ini untuk menelaah pemaknaan yang terdapat dalam karakter game Pokemon $\mathrm{GO}$, berdasarkan studi kasus yang dipilih, dengan menguraikan konteks pada ketentuan/konsep yang menjadi tanda visual melalui kajian estetik dari interaktivitas user. Kebudayaan, sistem nilai ataupun karakteristik bangsa Jepang merupakan wujud teks tertulis, sedangkan karakter game Pokemon merupakan teks berupa 
image.

Penelaahan dua komponen penelitian tersebut berdasarkan pada penelitian kualitatif deskriptif interpretatif dengan pendekatan studi kasus terhadap lingkup kajian estetik yang bertujuan untuk memahami peristiwa bermakna historis dengan penekanan perbedaan individu, sehingga dapat mengembangkan asumsi teori pada konteks dan waktu sebagai bahan penilaian etis/estetis atas terjadinya suatu fenomena (komunikasi) spesifik (Mulyana, 2001:20).

\section{HASIL PENELITIAN DAN PEMBAHASAN}

Game Pokemon GO, tergolong ke dalam genre RPG karena memiliki unsur storyline dan karakter yang sangat beragam di dalamnya. Ciriciri RPG yang mudah dijumpai dalam permainannya sendiri adalah apabila memasuki sesi battle atau pertarungan akan berpindah/berganti ke frame lain. Sedangkan secara detil ciri-ciri dari RPG dapat diuraikan sebagai berikut ini: Terdapat karakter musuh atau monster sepanjang permainan, Terdapat unsur leveling, inventory, skill, Terdapat unsur quest atau misi terhadap suatu kepentingan yang harus diselesaikan, Terdapat unsur item, magic, equip, dan shop untuk upgrading level karakter yang dimainkan, Memiliki gauge system seperti: HP, MP, SP, dan lain sebagainya.

Salah satu cara untuk menggambarkan alur interaksi dalam game adalah melalui alur cerita game itu sendiri. Dalam game Pokemon GO, alur interaksi bergerak searah/lurus dengan alur cerita yakni berawal dari start sampai finish. Alur interaksi yang ada dimulai dengan memilih karakter avatar serta Pokemon GO untuk dimainkan (berpetualang, bertarung dengan Pokemon liar maupun Pokemon milik trainer lain, dan lain sebagainya).

Evolution atau shinka dalam bahasa Jepang adalah perubahan wujud fisik yang terjadi pada Pokemon, mengarah kepada proses perkembangan tahapan metamorfosis daripada konteks 
evolusi yang sebenarnya, akibat adanya peningkatan stats values pada Pokemon. Evolusi yang terjadi pada Pokemon terjadi karena beberapa alasan, salah satunya akibat unsur penambahan battle experience yang menjadikan Pokemon lebih kuat daripada sebelumnya.

Evolusi Pokemon dapat dibagi menjadi beberapa tahapan berdasarkan pada asal atau tipe Pokemon itu sendiri. Semua Pokemon dibagi ke dalam empat kelompok yakni: baby Pokemon (wujud awal Pokemon), unevolved Pokemon (Pokemon yang tidak berevolusi), first-evolution Pokemon (wujud evolusi pertama Pokemon), dan second-evolution Pokemon (wujud evolusi kedua Pokemon).

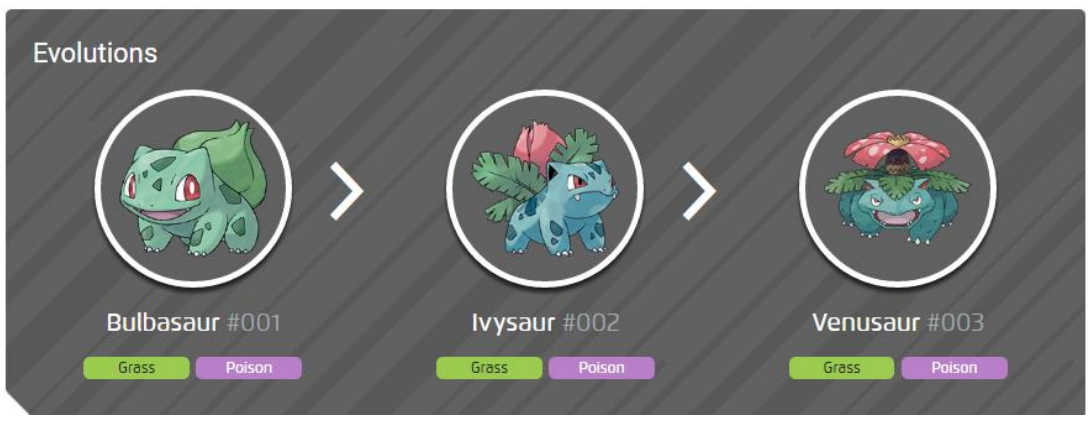

Gambar 5 Tingkatan evolusi Pokemon

Berdasarkan teori utama yang digunakan dalam penelitian ini, yakni manga- matrix yang pada dasarnya memiliki keterikatan dan saling melengkapi dengan teori game lain, objek kajian penelitian akan difokuskan mengenai pembahasan karakter dalam game Pokemon GO. Teori manga-matrix dipergunakan sebagai gambaran/referensi mengenai studi pengenalan terhadap penciptaan karakter, sebagai elemen dalam game yang dimainkan oleh para responden. Karakter Bulbasaur dipilih sebagai objek studi kasus penelitian sebagai karakter Pokemon yang dianggap cukup familiar bagi responden.

Bulbasaur ditampilkan sebagai karakter Pokemon hasil imajinasi dan kombinasi berbagai referensi citra hewan dan tumbuhan, dalam hal ini adalah Katak, kucing dan 
bunga bangkai. Pokemon ini Memiliki bentuk tubuh seperti katak berwarna hijau dengan bintik-bintik berwarna hijau tua di sekujur tubuhnya dan memilik telinga seperti kucing serta berjalan dengan empat kaki. Bulbasaur juga memiliki semacam kuncup bunga yang ada pada punggunya, ketika berevolusi, kuncup tersebut akan merekah menjadi bunga bangkai. Kuncup inilah yang menjadi kekuatan utama yang dimiliki oleh Bulbasaur.

\section{Analisis Visual Desain Karakter Bulbasaur Pada Game Pokemon GO}

Morphological

Forced

Connections merupakan teknik awal yang digunakan untuk menghubungkan beberapa parameter/elemen visual yang terdapat pada karakter Bulbasaur objek kajian dalam penelitian ini, seperti yang ditunjukkan pada Tabel dibawah ini :

Tabel 2 Matriks Karakter Bulbasaur

\begin{tabular}{|l|l|l|l|l|l|l|}
\hline $\begin{array}{c}\text { Karakter } \\
\text { Bulbasaur }\end{array}$ & Mata & Telinga & Hidung & Mulut & Tubuh & Kaki \\
\hline
\end{tabular}

Pada tabel diatas memperlihatkan pembagian unsur-unsur visual karakter Bulbasaur yang menjadi parameter dalam analisis yang akan dipaparkan secara lebih detil terkait dengan perubahan visual karakter Bulbasaur. Pembagian elemen visual karakter Bulbasaur tersebut dilakukan berdasarkan fisiologi dasar tampilan yang menjadi pengenal/identitas pengenal suatu makhluk hidup antara lain: bagian muka (mata, hidung, mulut, telinga) dan bagian badan (kaki, dan warna kulit/tubuh).

Tabel 3 Matriks Struktur Anatomi Bulbasaur

\begin{tabular}{|c|c|c|c|c|c|c|}
\hline $\begin{array}{c}\text { Karakter } \\
\text { Bulbasaur }\end{array}$ & Mata & Telinga & Hidung & Mulut & Tubuh & Kaki \\
\hline
\end{tabular}




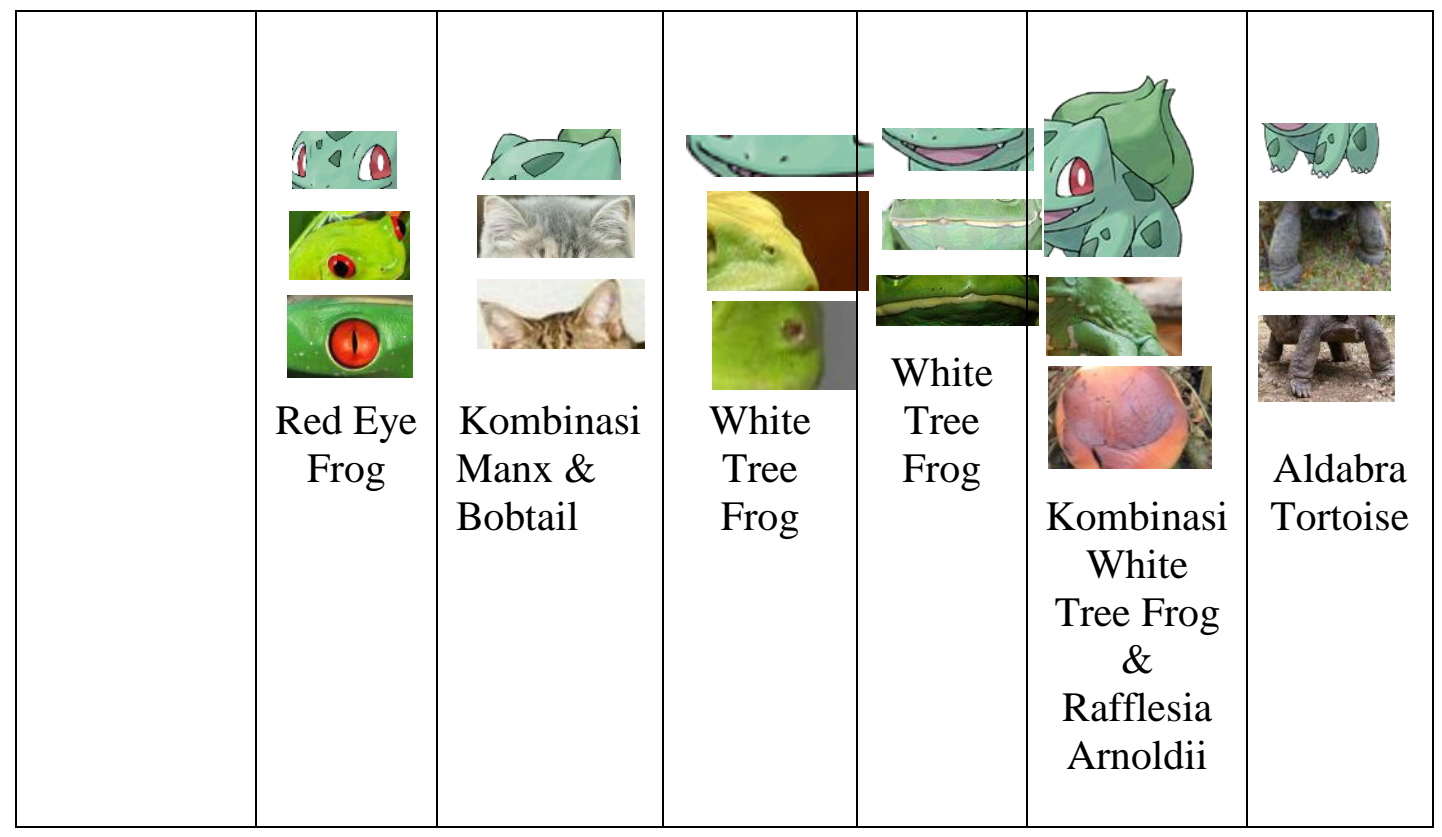

Tahapan selanjutnya adalah Bulbasaur dapat dikategorikan ke pemaparan mengenai pemecahan dalam mata golongan hewan Red elemen karakter Bulbasaur berdasarkan struktur anatominya. Pemecahan struktur anatomi Bulbasaur berdasarkan pada tiga jenis hewan yakni : Katak (Red Eye Frog dan White Tree Frog), kucing (Manx dan Bobtail), dan KuraKura (Aldabra Tortoise) Serta satu jenis tumbuhan yakni Rafflesia Arnoldii. Pemecahan elemen desain karakter Bulbasaur dikaitkan dengan struktur anatomi pada Tabel di atas, tampak terlihat beberapa kombinasi antara hewan amfibi dari Red Eye Frog dan White Tree Frog. Pada tabel mata Eye Frog. Sedang pada tabel telinga dikategorikan dalam golongan hewan mamalia yaitu Manx dan Bobtail. Sedangkan tabel hidung menampilkan ciri hewan White Tree Frog, dan tabel mulut menampilkna ciri hewan White Tree Frog. Bagian tubuh menampilkan ciri dari hewan White Tree Frog dan sekaligus kombinasi penambahan dari tumbuhan Rafflesia Arnoldii. Sedangkan tabel bagi kaki menampilkan ciri dari hewan reptil yaitu Aldabra Tortoise yang memiliki corak pada bagian kaki.

Tabel 4 Matriks Morphological Forced Connections Karakter Bulbasaur 


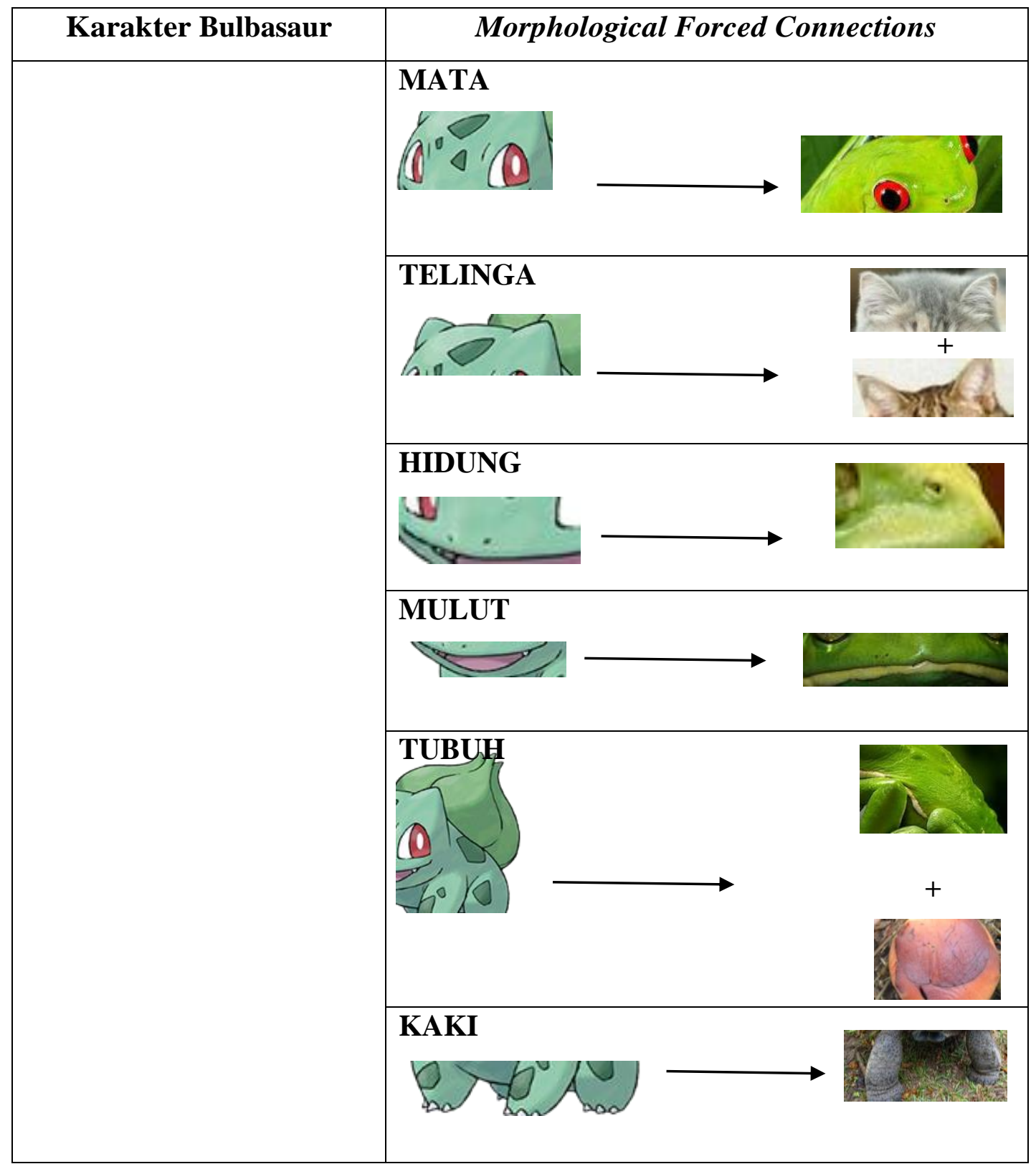

Pada Tabel di atas Matriks karakter Bulbasaur. Karakter Morphological Forced Bulbasaur memiliki konsep awal Connections Karakter Bulbasaur, sebagai amfibi dengan berwarna elemen-elemen penelusuran awal hijau dan memiliki corak hijau tua yang terdapat pada Tabel Matriks pada tubuhnya, serta penambahan Struktur Anatomi Bulbasaur mulai tumbuhan Rafflesia Arnoldii. terlihat alur pencipta kreator Bulbasaur digambarkan memiliki 
mata berwarna merah, telinga besar, serta memiliki empat kaki bercakar. Secara umum, tampilan karakter Bulbasaur menampilkan karakteristik yang ada pada hewan White Tree Frog, yakni katak berukuran gemuk yang ditemukan pada pepohonan yang dekat sumber air. Katak ini bisa hidup di rawa-rawa atau di rerumputan yang bersuhu sejuk. Katak ini adalah hewan nocturnal, aktif di malam hari dan biasa ditemukan pada daerah Australia Utara, New Guina, Indonesia \& Selat Torres. Karakter Bulbasaur dan turunan wujud perubahannya (Evolusi) memiliki karakteristik hewan katak, kucing, dan kura-kura di tambah dengan tumbuhan Rafflesia Arnoldii yang menjadi ciri khas Bulbasaur.

Perbandingan transformasi visual karakter Bulbasaur dan evolusinya dengan penerapan gagasan pencitraan dari penciptaan karakter yang ada melalui teori Mangamatrix yakni penerapan suatu kombinasi gagasan terhadap bentuk, wujud, maupun komposisi di dalamnya. Elemen tersebut kemudian diolah sedemikian rupa, sehingga rumusan dasar dari gagasan penciptaan karakter yang cukup familiar dan memudahkan bagi pengamat untuk dapat mengenali perubahan yang terjadi, baik wujud awal maupun wujud akhirnya dapat diketahui dan mudah dikenali oleh pengamat.

Tabel 5 Perbandingan transformasi visual karakter Bulbasaur

\begin{tabular}{|l|c|c|c|}
\hline \multicolumn{2}{|c|}{ Karakter Awal } & Evolusi 1 & Evolusi 2 (Akhir) \\
\hline \multicolumn{3}{|c|}{ Citra / Image yang bertahan } \\
\hline Parameter & Bulbasaur & Ivysaur & Venusaur \#003 \\
\hline \multicolumn{3}{|c|}{} \\
\hline
\end{tabular}




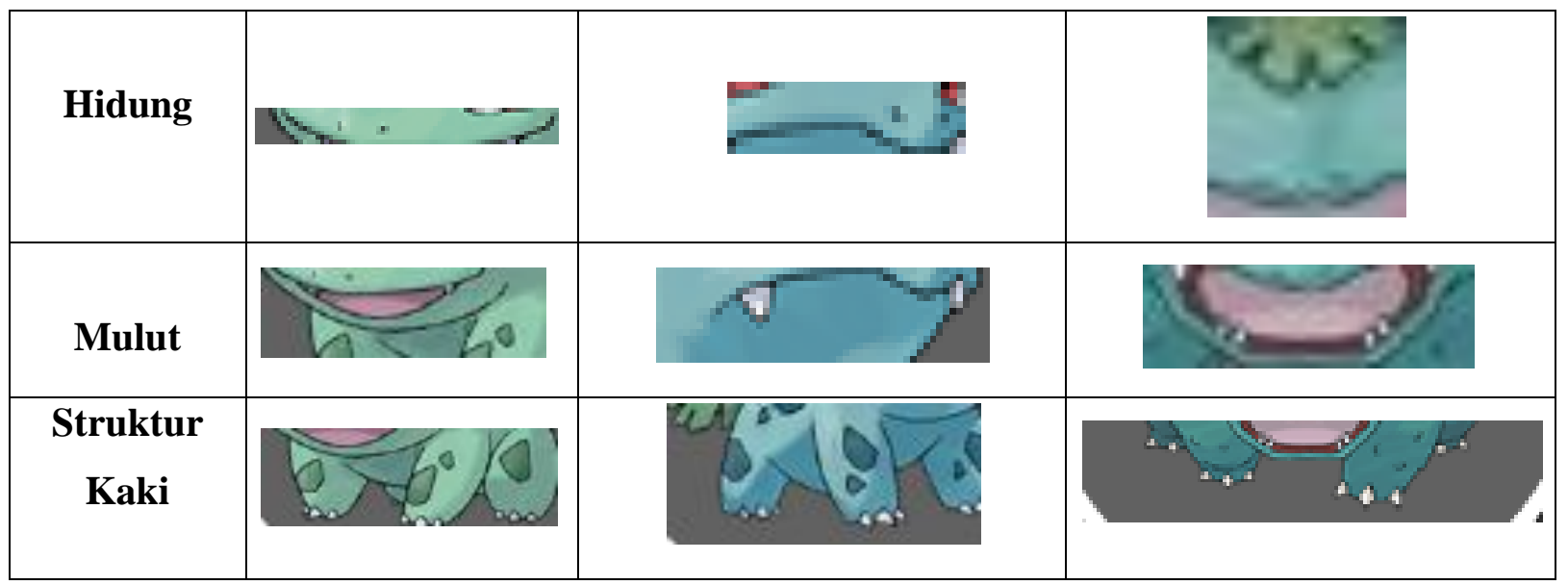

\begin{tabular}{|c|c|c|c|}
\hline \multicolumn{3}{|c|}{ Citra / Image yang berubah } \\
\hline Mata & Struktur \\
Telinga & Struktur & & \\
Tubuh & & & \\
\hline
\end{tabular}

Tabel 6 Analisis Transformasi Visual Karakter Bulbasaur Berdasarkan Mitologi Jepang

\begin{tabular}{|c|c|c|c|}
\hline Objek & Referensi & Posisi & Keterangan \\
\hline & Gama's Toad & $\begin{array}{c}\text { Masyarakat jepang } \\
\text { percaya bahwa katak } \\
\text { merupakan hewan } \\
\text { pembawa } \\
\text { keberuntungan dan } \\
\text { juga bermakna } \\
\text { membawa keselamatan } \\
\text { dalam perjalanan, } \\
\text { membawa kembali } \\
\text { barang-barang hilang, } \\
\text { dan mendatangkan } \\
\text { rezeki. }\end{array}$ & $\begin{array}{l}\text { Konsep dari mitologi } \\
\text { jepang yaitu Gama's } \\
\text { Toad peliharaan dari } \\
\text { Gama Sennin. }\end{array}$ \\
\hline
\end{tabular}




\begin{tabular}{|c|c|c|c|}
\hline & $\begin{array}{c}\text { Karakteristik hutan } \\
\text { hujan tropis dengan } \\
\text { pepohonan yang } \\
\text { rimbun }\end{array}$ & $\begin{array}{c}\text { Konsep Shizen } \\
\text { (Keselarasan Alam) }\end{array}$ \\
& & \\
\hline
\end{tabular}

Tabel 7 Psikologi Warna karakter Bulbasaur

\begin{tabular}{|c|c|c|}
\hline Objek & Warna & Keterangan \\
\hline Karakter Awal Bulbasaur & $\begin{array}{l}B D 616 A \\
\text { FFFFFF } \\
855297 \\
467450\end{array}$ & $\begin{array}{l}\text { Pada karakter awal warna yang } \\
\text { digunakan terdiri dari } 4 \text { warna yakni } \\
\text { merah, putih, hijau muda dan hijau } \\
\text { tua. } \\
\text { Dari ke empat warna tersebut } \\
\text { memiliki psikologi yang berbeda- } \\
\text { beda. } \\
\text { - Warna Merah dalam masyarakat } \\
\text { jepang melambangkan kekuatan. } \\
\text { - Warna Putih yang memiliki arti } \\
\text { dalam masyarakat jepang } \\
\text { kesucian. } \\
\text { - Warna hijau muda dan tua } \\
\text { dalam masyarakat jepang } \\
\text { memiliki arti kesopanan. }\end{array}$ \\
\hline $\begin{array}{c}\text { Karakter Evolusi Awal } \\
\text { Bulbasaur }\end{array}$ & 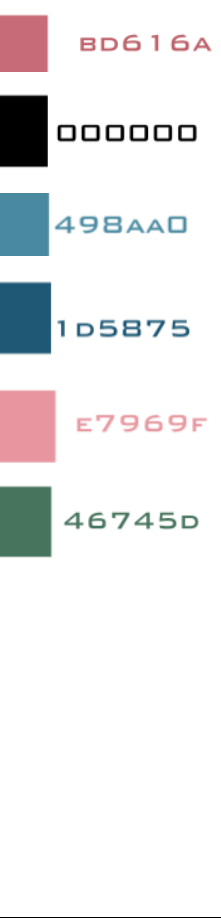 & $\begin{array}{l}\text { Pada karakter evolusi awal warna } \\
\text { yang digunakan terdiri dari } 6 \text { warna } \\
\text { yakni merah, hitam, biru muda dan } \\
\text { biru tua, merah jambu, dan hijau. } \\
\text { Dari ke enam warna tersebut } \\
\text { memiliki psikologi yang berbeda- } \\
\text { beda. } \\
\text { - Warna Merah dalam masyarakat } \\
\text { jepang melambangkan kekuatan. } \\
\text { - Warna Hitam merupakan warna } \\
\text { tertua di Jepang yang memiliki } \\
\text { arti dalam masyarakat jepang } \\
\text { serius dan misterius. } \\
\text { Warna Biru muda dan tua } \\
\text { Kental dengan nuansa rasa } \\
\text { kepercayaan dan keamanan. } \\
\text { Warna merah jambu } \\
\text { melambangkan sikap yang }\end{array}$ \\
\hline
\end{tabular}




\begin{tabular}{|c|c|c|}
\hline & & $\begin{array}{l}\text { mencintai antar sesama. } \\
\text { - Warna hijau tua dalam } \\
\text { masyarakat jepang memiliki arti } \\
\text { kesopanan. }\end{array}$ \\
\hline $\begin{array}{c}\text { Karakter Evolusi Akhir } \\
\text { Bulbasaur }\end{array}$ & $\begin{array}{l}\text { BD616A } \\
\text { 498AAD } \\
\text { 1 D5875 } \\
\text { E7969F } \\
\text { 46745D } \\
\text { FFFFFF } \\
\text { B०6854 } \\
\text { C68102 }\end{array}$ & 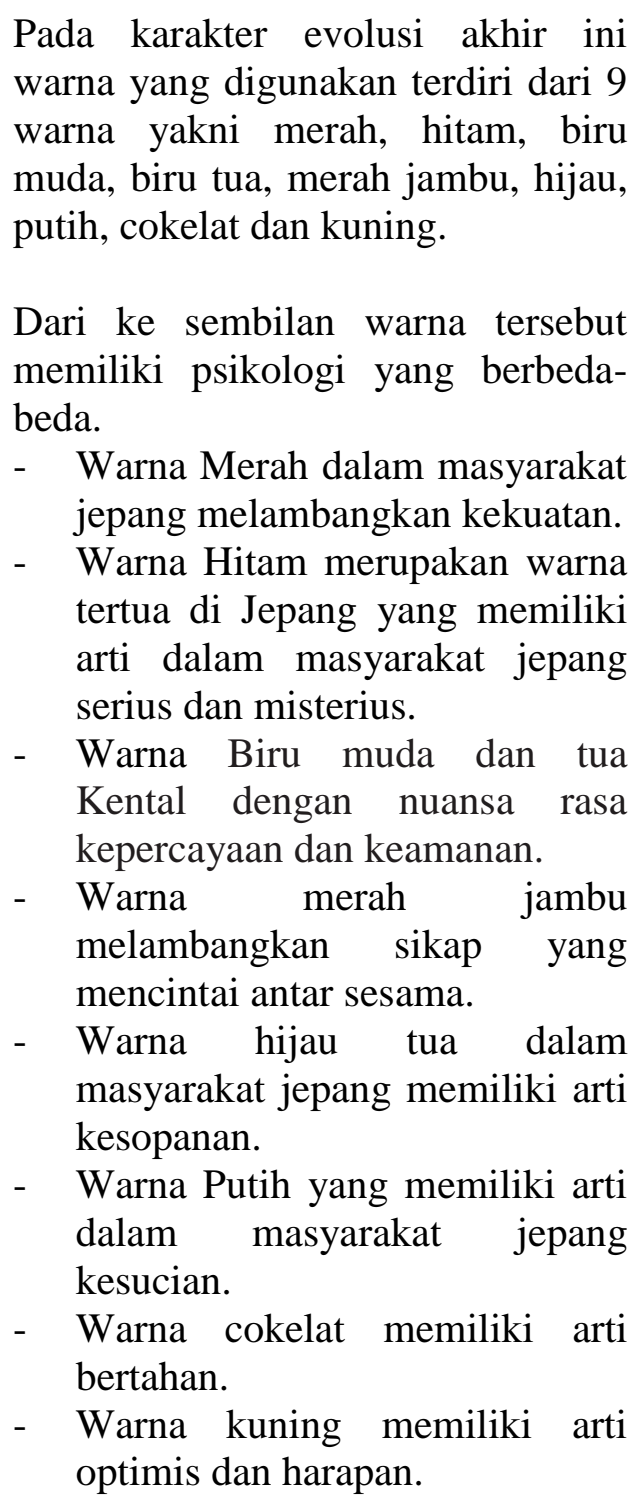 \\
\hline
\end{tabular}

\section{PEMBAHASAN}

Berdasarkan hasil penelitian diatas, maka pembahasan mengenai karakter Bulbasaur dan turunan perubahan wujud atau bentuk transformasi (evolusi) yang ada pada game Pokemon GO dapat diuraikan sebagai berikut: 
1. Terdapat

perubahan

(transformasi) terhadap elemen-

elemen yang berkaitan dengan

tampilan grafis karakter secara menyeluruh seperti image hewan karakter, dimensi tubuh, dan warna.

2. Perubahan warna yang terjadi pada karakter Bulbasaur, Ivysaur, dan Venusaur terkait pada warna tubuh dan beberapa bagian tubuh, secara tidak langsung mengindikasikan kekuatan antara satu dengan yang lain.

3. Elemen perubahan terdapat pada bagian tubuh yang mewakili image representatif dari hewan yang ada di dunia nyata meliputi mata, telinga, hidung, mulut, tubuh dan kaki sesuai dengan karakteristik elemen yang dimilikinya.

4. Elemen dan warna yang terdapat pada Bulbasaur dan turunannya merupakan gambaran singkat dari elemen kehidupan yakni: pohon (Hutan Hujan Tropis) dengan Konsep Shizen (Keselarasan Alam).

5. Karakter Bulbasaur terinspirasi dari hewan Amfibi seperti katak yang memiliki beragam jenis.

6. Hewan katak dengan berbagai macam jenisnya merupakan salah satu dari sekian banyak jenis hewan mitologi di Jepang. Adanya faktor tradisi dari mitologi Jepang tentang peranan hewan katak, masyarakat jepang percaya bahwa katak merupakan hewan pembawa keberuntungan dan juga bermakna membawa keselamatan dalam perjalanan, membawa kembali barang-barang hilang, dan mendatangkan rezeki.

\section{SIMPULAN}

Salah satu ciri yang mendasar dari Pokemon adalah terdapat unsur transformasi (evolusi) di dalamnya, yakni perubahan wujud suatu Pokemon dari wujud awal menjadi wujud yang lebih kuat. Konsep transformasi yang ada dalam game Pokemon GO sebagai wujud penggabungan fiksi dengan teori ilmiah. Adanya transformasi (Perubahan) karakter dalam dunia Pokemon terjadi akibat faktor experience, kenaikan level disertai 
kenaikan kemampuan (ability)

Pokemon yang bersangkutan.

Namun, satu hal penting dalam

dunia Pokemon adalah bahwa tidak semua Pokemon mengalami proses transformasi. Sebagian Pokemon tetap dalam wujud awalnya walaupun telah dikenai atau mengalami berbagai macam perlakuan terhadapnya. Melalui analisis data yang telah dilakukan, teridentifikasi bahwa wujud transformasi Pokemon memiliki persamaan dengan wujud awalnya. Adanya elemen-elemen tambahan pada wujud transformasi Pokemon tertentu telah memberikan keragaman bentuk pada visualisasi karakter Pokemon. Ragam bentuk Pokemon tersebut menjadi dasar penciptaan karakter sebagai media pengenalan transformasi visual desain karakter suatu game. Hasil analisis mengenai transformasi visual desain karakter game Pokemon GO didapat sebagai berikut:

1. Warna pada desain karakter game Pokemon GO merupakan warna sekaligus objek pembentuk lingkungan (environment) yang diminati pemain karena banyak menggunakan pilihan warna cerah dan colourful.

2. Tema yang ditampilkan dalam game Pokemon GO menampilkan unsur interaksi antar makhluk hidup, persahabatan, dan perdamaian sesuai dengan filosofi dalam kebudayaan Timur seperti: filosofi Taoisme (Cina) maupun paham naturalisme Buddha atau Shizenshugi (Jepang), sangat disukai dan sesuai untuk semua kalangan umur.

3. Visualisasi desain karakter Pokemon sebagian besar dibuat berdasarkan karakteristik hewan yang ada di sekitar manusia. Dalam dunia desain hal ini disebut pengembangan desain Organic-Animal Analogy, sebagai salah satu metode penciptaan karakter Pokemon dari hasil penganalogian hewan asli.

Secara keseluruhan tampilan visual desain karakter Pokemon yang ada merupakan hasil dari terapan metode Manga matrix yang 
berperan dalam setiap proses transformasi visual desain untuk menciptakan karakter Pokemon yang tidak terbatas. Penelitian ini merupakan tahap awal pengenalan teori Manga-matrix, teknik morphological forced connections, serta teori warna sebagai metode untuk menciptakan karakter. 


\section{DAFTAR PUSTAKA}

Creswell, J.W. 2007. Qualitative Inquiry and Research Design Choosing Among Five Approaches, USA: Sage Publication.

Darmaprawira, S. 2002. Warna-Teori dan Kreativitas Penggunaannya, Edisi ke-2, Bandung: Penerbit ITB.

Koberg, D. \& Bagnall, J. 1981. The All New Universal Traveler, California: William Kaufmann.

Mulyana, D. 2001. Metodologi

Penelitian Kualitatif -

Paradigma Baru Ilmu

Komunikasi dan ilmu Sosial

Lainnya, Bandung: PT. Remaja

Rosdakarya.

Samara, Timothy, 2003. Design elements, A Grapich Style manual. New York : Rockport Publisher.

Schell, J. 2008. The Art of Game DesignA Book of Lenses. Burlington: Morgan Kaufmann Publishers

Suryohadiprojo, S. 1982. Manusia dan Masyarakat Jepang dalam Perjoangan Hidup, Jakarta: UI Press dan Pustaka Bradjaguna.

Tsukamoto, H. 2006. Manga Matrix: Create Unique Characters Using the Japanese Matrix System, USA: Collins Design. 